\title{
Perception of cuts in different editing styles
}

\author{
Celia Andreu-Sánchez; Miguel-Ángel Martín-Pascual
}

Nota: Este artículo se puede leer en español en:

http://www.profesionaldelainformacion.com/contenidos/2021/mar/andreu-martin_es.pdf

How to cite this article:

Andreu-Sánchez, Celia; Martín-Pascual, Miguel-Ángel (2021). "Perception of cuts in different editing styles". Profesional de la información, v. 30, n. 2, e300206.

https://doi.org/10.3145/epi.2021.mar.06

Manuscript received on $18^{\text {th }}$ May 2020 Accepted on $12^{\text {th }}$ July 2020



Celia Andreu-Sánchez $\square$ https://orcid.org/0000-0001-9845-8957 Serra Húnter Fellow Universitat Autònoma de Barcelona Dep. de Com. Audiovisual i Publicitat Neuro-Com Research Group Edifici I. Campus Bellaterra. 08193 Cerdanyola del Vallès (Barcelona), Spain celia.andreu@uab.cat

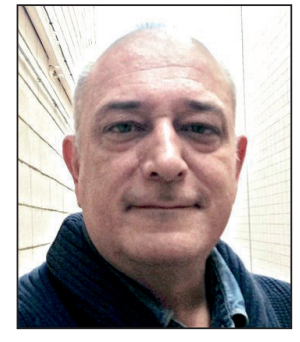

Miguel-Ángel Martín-Pascual https://orcid.org/0000-0002-5610-5691 Technological Innovation IRTVE Instituto RTVE (Barcelona) Corporación Radio Televisión Española Universitat Autònoma de Barcelona Dep. de Com. Audiovisual i Publicitat Neuro-Com Research Group miguelangel.martin@rtve.es

\begin{abstract}
The goal of this work is to explain how the cuts and their insertion in different editing styles influence the attention of viewers. The starting hypothesis is that viewers' response to cuts varies depending on whether they watch a movie with a classical versus a messy or chaotic editing style. To undertake this investigation, we created three videos with the same narrative content and duration but different editing styles. One video was a fixed one-shot movie. Another video followed a classical editing style, based on the rules of classic Hollywood movies, according to David Bordwell's studies. The other video used a chaotic style, beyond post-classic, which broke the classical rules of continuity and was inspired by music video clips. We showed these stimuli to 40 subjects while recording their brain activity using the electroencephalography (EEG) technique. The results showed that cuts reduce the eyeblink frequency during the second after they are seen. Since blinking is a well-known attention marker, we propose that cuts increase viewers' attention. Cuts initiate a flow of electrical activity from the visual cortex to the cognitive processing zone in the prefrontal area. We also found that the different editing styles in which cuts are inserted affected perception, confirming the initial hypothesis. These results could be of great interest and utility for creators of audiovisual content and the management of attention in their work.
\end{abstract}

\section{Keywords}

Cuts; Audiovisual editing; Perception; Attention; Neurocinematics; Electroencephalography; Blinking; Visual cortex; Classical editing style; Post-classical editing style.

\section{Introduction}

Audiovisual content is full of stylistic features that help shape its narrative discourse. One such resource is the editing style, which has been of great interest in the field of communication and attention management since the origins of cinema (Münsterberg, 1916; Bordwell; Staiger; Thompson, 1985), with the cut being its basic operational tool (Germeys; D'Ydewalle, 2007; Andreu-Sánchez et al., 2018). The aim of the current work is to determine how viewers manage their attention while watching videos with different editing styles. To address this, we used both viewers' blinks as attention markers and viewers' electrical brain activity in comparative experiments with different editing styles to study the attentional effect of cuts on viewers' brain by analyzing the causality and potential activity in occipital and prefrontal areas associated with vision and cognitive processes (Andreu-Sánchez et al., 2017a; 2017b; 2018).

\subsection{Neurocinematics: neuroscience and communication}

The study of audiovisual perception using neuroscientific tools dates back to the 1950s, when Gastaut and Bert presented films to normal subjects and to patients with neurotic disorders to verify the differences in the effects of cinemato- 
graphic projections on the psychic states of the viewers (Cohen-Séat; Gastaut; Bert, 1954; Gastaut; Bert, 1954). This was the first time that films were used to analyze electroencephalographic activation in psychology and psychiatry and, by extension, in ordinary viewers. By selecting control films and films capable of inducing emotional reactions, they found patterns in the viewers' perception of cinematographic narrative content. They discovered the en arceau rhythm, today known in scientific literature as the mu rhythm, which appeared throughout the film's projection at moments of emotional involvement or high empathy with the content of the films. The role of simulation and projection onto the actions of others in visual perception was clearly established. It was not until 1999, 45 years later, that Gastaut's discoveries about the desynchronization of these "arc" rhythms (or mu rhythms) were reproduced, when looking at the motor actions of others (Cochin et al., 1999). Stephanie Cochin's team from the neurophysiology service in Tours, France, employing 10 subjects observing and executing finger movements, demonstrated that the observation and execution of movements shared the same cortical network. Gradually, the suppression of mu in the premotor cortex acquired fundamental importance, which was debated but confirmed, with respect to the response of the activity of the mirror neuron system (MNS) and its activation when watching others do things (Rizzolatti; Craighero, 2004) or an action scene in a movie.

The early years of the $21^{\text {st }}$ century saw new works that developed the study of communication and cinema using neuroscientific tools. A group of scientists from Israel, led by Uri Hasson, analyzed the synchronization between the cortical activity of different subjects while viewing the film The Good, the Bad and the Ugly (Hasson et al., 2004). Their discovery of a pattern of synchronized consumption among viewers while watching the same movie led them to denote this stream of research using the term neurocinematics (Hasson et al., 2008).

Since then, research into the perception of audiovisual content, and communication in general, using tools and techniques that are typical of neuroscience has undergone great development, consolidating itself as a discipline that offers results of vital importance for the design of audiovisual messages.

\subsection{Blinking}

Although we are not aware of it, we blink constantly while awake. Each blink lasts between 150 and 400 milliseconds (Stern; Boyer; Schroeder, 1994; Shapiro; Arnell; Raymond, 1997; Skotte et al., 2007), during which visual information is hidden from us. Blinking has the basic physiological function of wetting the cornea (Bour; Aramideh; Ongerboer-de-Visser, 2000; Delgado-García; Gruart; Múnera, 2002), and an insufficient blink rate can lead to eye health problems (Blehm et al., 2005). However, it also has a psychological function (Fogarty; Stern, 1989), being a marker of attention: indeed, when we pay more attention to a visual stimulus, we blink less (Wong; Wan; Kaye, 2002).

As early as 1995, sound designer and film editor Walter Murch wondered about the relationship between the timing of blinks and film editing (Murch, 1995). Having worked in Hollywood for many years as an editor or sound designer on Apocalypse Now and The Godfather among other films, Murch suspected that blinking played a role in understanding films. He hypothesized that the blink rate might be synchronized between the viewers of a movie and thus wondered whether there is an objective blink that can warn editors about the ideal time to change a shot in the editing room. Today we know that this is not exactly the case, as the cutoff point depends on many other narrative factors. A classical audiovisual narrative must

- minimize awareness of a cut,

- create the perception of continuity across a cut, and

- achieve that the expectations associated with this continuity can be resolved after the cut (Smith, 2012).

However, when viewing audiovisual content, viewers often do not consciously perceive cuts between shots due to a kind of edit blindness (Smith; Henderson, 2008). This parallels the psychological concept of attention blindness in the visual perception of reality and its division into attentional events that we unconsciously make (Zacks et al., 2007; Magliano; Zacks, 2011). The process of blinking is a marker akin to cuts in editing. A perceptual suppression mechanism is biologically triggered to achieve the sensation of observing a continuous reality (Bristow et al., 2005). We do not notice blinks until we think about them.

Therefore, blinking can be used as a tool to quantify the audience's attention to different audiovisual content. Studies have shown that blinks can be linked to the perception of narrative content presented through different formats, mainly videos and audios (Nakano et al., 2009).

\subsection{Electrical brain activity}

Our brain is also constantly working. Whether we are active or at rest, our neurons exhibit electrical activity that can be recorded by electroencephalography (EEG). This technique was first applied to humans in 1929 by the German psychiatrist Hans Berger (Berger, 1929). EEG can detect and analyze the electrical activity in the brain through electrodes placed invasively (using surgery for direct placement in the brain) or non-invasively (through the skull). 
For many years, prior to the EEG technique, it was believed that the brain was compartmentalized into different areas with very concrete and specific functions. The theory that developed this idea is phrenology, whose main promoter was Franz Joseph Gall (although he never approved this term) (Zola-Morgan, 1995). According to this theory, the brain is compartmentalized into areas with different tasks such as friendship, courage, the tendency to steal, ambition, or vanity, among others. Years later, science found that, although there is specialization in areas of the brain, the brain is not as compartmentalized and works more globally than Gall's proposal. Today, we know that there are specific areas for vision, hearing, or language, among others, but localization theories have given way to the study of the brain as a connected network. Vernon Mountcastle showed how the regions of the cortex that manage auditory input resemble those that manage touch and muscle control, Broca's language area, and any other region of the cortex (Mountcastle, 1978; Mountcastle, 1998). He suggested that, since all these regions are similar, they may be performing the same operation, and proposed that the cortex uses a common algorithm to accomplish everything it does. It is how the regions are connected that defines their apparently different cognitive functions. So, different parts of the brain work in synchronization and/or causality with each other. Even the connectivity patterns are characteristic of each subject, like a fingerprint of their cognitive processes (Finn et al., 2015).

The brain processes associated with vision perception are very fast, but quantifiable and localized in cognitive areas. Simon Thorpe and his team presented photographs of animals in the jungle and photographs of the jungle without animals (Thorpe; Fize; Marlot, 1996; VanRullen; Thorpe, 2001). The EEG signals were the same when one or another photograph was presented, but after 150 milliseconds they began to differentiate depending on the presence or absence of the animal. Some early brain process had already decoded the information to discriminate. It is estimated that the signal from the retina (via the magnocellular pathway, the action-oriented visual information pathway) to area $\mathrm{V} 1$ in the occipital area of the brain arrives in 35 milliseconds. That leaves barely 115 milliseconds to activate the ventral network (the parvocellular pathway for identification and recognition of what we see) and still further towards the prefrontal area of the brain for information extraction (Milner; Goodale, 2006). This time is very tight, as the reaction time of a neuron to a synaptic input, although variable, is 5-10 milliseconds (Byrne, 2015), albeit happening massively, in parallel, and discontinuously (VanRullen, 2007). The fact that the brain deduces this information does not mean that it is conscious; rather we notice that something happens after 150 milliseconds. It may take longer, at least 250 milliseconds, to consciously decide and to be able to say that we "see" something and what it is. With techniques such as EEG, it is possible to temporally analyze the effect of cuts on the brain, whether or not we are aware of them.

\section{Methods}

The goal of this work is to show the cognitive processing of viewers while they consume videos. Specifically, we are interested in seeing how the cuts and their insertion in different editing styles influence viewers' attention.

The initial hypothesis is that viewers' response to cuts varies depending on whether they are watching a movie with a classical versus a messy and chaotic style. This can have consequences for the design of effective narratives on all audiovisual platforms. To carry out this research, we created three videos with the same narrative content and length but different editing styles.

The materials and methods used during this work are presented below. For more information regarding this study, refer to previous works by the authors, on which this article is based (Andreu-Sánchez et al., 2017a; 2017b; 2018; Martín-Pascual et al., 2018).

\subsection{Participants}

Forty subjects ( 31 men and 9 women) participated in this research, aged between 28 and 56 years. Half of the subjects (20) were audiovisual professionals from Radio Televisión Pública Española (RTVE). Data from all 40 subjects were used for the blink frequency analysis, while the data recorded from 36 of the subjects were used for the analysis of the electroencephalographic recordings. The subjects had good or corrected visual acuity. All subjects participated voluntarily in this study and gave prior written informed consent. The experimental sessions and analyses were developed in accordance with the main guidelines and regulations on the ethics of research with humans, and the protocols were approved by the Ethics Committee for Research with Animals and Humans (Ceeah) of the Autonomous University of Barcelona, Spain.

\subsection{Stimuli}

We designed a narrative lasting approximately three minutes (198 seconds) that we shot and edited following three different editing styles, thus creating three video stimuli. In the first stimulus, we used a fixed-shot camera sequence with no cuts or changes in perspective during the entire one-shot movie. In the second stimulus, we applied classical audiovisual editing, with general shots, mid-planes, close-ups, and details, always with continuity between shots and with organization. This video followed the classical Hollywood editing style (Bordwell; Staiger; Thompson, 1985). During the 198 seconds of this stimulus, 33 shots were presented, with an average duration per shot of 5.9 seconds. The third video stimulus using a post-classical style that broke the continuity and classical organization, being chaotic and disorganized, with overhead shots, low-angle shots, large general shots, breaking of the $180^{\circ}$ rule, and breaking of continuity in space and time. During this stimulus, also lasting 198 seconds, 79 shots were presented, with an average duration per shot of 2.4 seconds. It followed a style inspired by music video clips. 


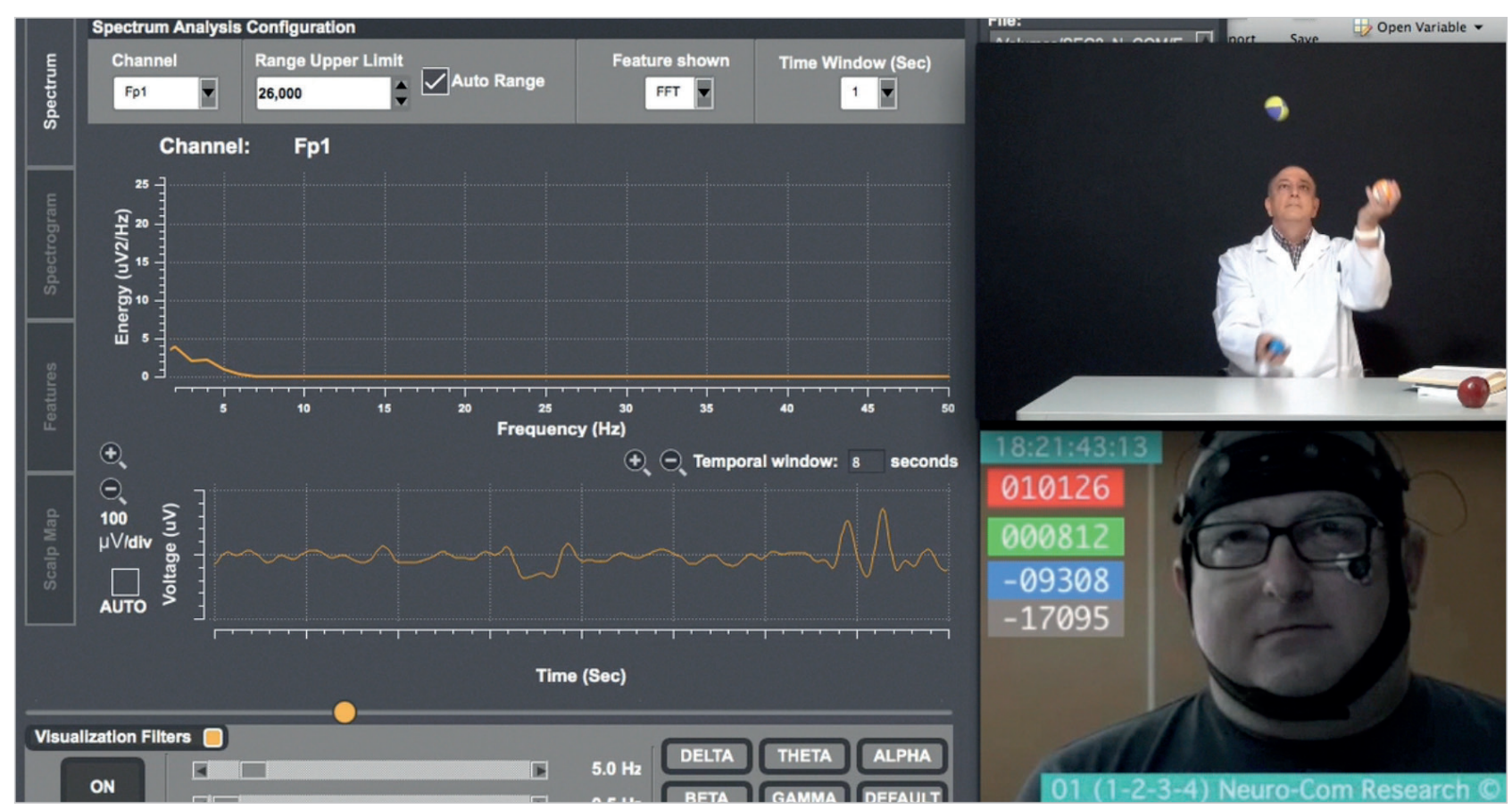

Figure 1. Experimental recording session with one of the subjects. On the left, the screen of the EEG recording software; on the right above, a frame from one of the videos presented to the subjects. On the right below, one of the participants. To facilitate the analysis of the random representation of the stimuli, a chromatic protocol was designed. Source: own elaboration, for educational purposes, and with the consent of the people who appear in the image.

These video stimuli were presented randomly to the subjects. The videos were shown on a 42-inch high-definition (HD) light-emitting diode (LED) display screen from Panasonic. The subjects were positioned 150 centimeters in front of the screen. All the stimuli were synchronized with the brain electrical activity recording device, in order to achieve good correspondence between the dependent variables (blinks and brain activity) and independent variables (edited video stimuli).

\subsection{Electroencephalographic recordings}

To record the electrical activity of the brain and the blinking of the subjects, we used the electroencephalography (EEG) technique. This technique makes it possible, through the use of noninvasive electrodes, to obtain the electrical activity of certain brain areas while performing a task or perceiving a specific stimulus. Likewise, it is an excellent tool to detect and acquire participant blinks. We used a 20-channel wireless EEG from Enobio from Neuroelectrics. We placed the electrodes according to the international standard 10-20 system with an electrode for the electrooculographic recording of the subjects, so that we could easily detect the aforementioned blinks.

Note that, to triangulate the data, we also recorded the subjects' faces during the experimental sessions (Figure 1) using a Sony HD camera (model HDR-GW55VE) at 25 frames per second.

\subsection{Software}

In this research we used various software packages. To present the stimuli on the screen and to synchronize them with the EEG, we used Paradigm Stimulus Presentation (from Perception Research Systems Inc.). For EEG recording, we used NIC software (Neuroelectrics). These two software packages were synchronized to the millisecond using commands and code plugins developed jointly with the manufacturer of the stimulus presentation software, in order to obtain a perfect correspondence between the variables. To analyze the records, filter the data, and obtain a list of blinks of the participants, we used Matlab 2013a (MathWorks), Eeglab, and Brainstorm. For statistical analysis, we used SigmaPlot 11.0 (Systat Software).

\subsection{Analysis}

To detect and analyze blinks, we first determined how many blinks each subject made while viewing each of the presented stimuli, and calculated the corresponding blink rate per minute. Next, we constructed a table of the data and applied different statistical, parametric, and nonparametric studies based on the Shapiro-Wilk test to determine the normality of the data using an alpha level of 0.05 . We carried out repeated-measures analysis of variance and post hoc analysis using various methods, as mentioned in each of the sections of this article.

\section{Results}

\subsection{Differences in blink rate between editing styles}

We found that the mean blinking rate of the subjects was $13,776 \pm 9,641$ blinks/minute when watching the one-shot movie, 13,427 $\pm 9,338$ blinks/minute when watching the stimulus with the classical and organized editing style, and $12,421 \pm 8,283$ blinks/minute when watching the video with post-classical and chaotic editing. In general, the number of 
blinks per minute decreased as the number of cuts was increased for all the participants (Andreu-Sánchez et al., 2017). The statistical comparison confirmed that these results were significant $\left(\chi^{2}(2)=7.2, p=0.027\right.$, Friedman's nonparametric test). Pairwise comparison revealed statistical significance only between the one-shot video and the post-classical chaotic style $(p<0.05$, Tukey post hoc test for Friedman's test, Dunn post hoc test for Friedman's test, and post hoc Student-Newman-Keuls test for Friedman's test).

To confirm these results, we carried out another pairwise comparison between the editing styles for each group of subjects independently. The results showed that the spectators' blink rate was significantly different between the one-shot video and the post-classical editing style in the case of the group of non-media professionals $(W=-132, Z=-2.464, p$ $=0.012$, Wilcoxon signed-rank nonparametric test). However, such a difference did not occur among the media professionals.

When comparing the blink frequency after a cut with that of the rest of the stimulus, we found (Andreu-Sánchez et al., 2018) that the blink rate decreased significantly during one second after a cut with respect to the rest of the stimulus $(t(35)=-2.719, p=0.001$, t-test). This suggests that the cut has an effect on the viewer's blinking.

\subsection{Brain activity differences between editing styles}

Based on the analysis of the spectral power of the EEG, we found (Andreu-Sánchez et al., 2018) statistically significant differences ( $p<0.05, t$-test) at $200 \mathrm{~ms}$ and $400 \mathrm{~ms}$ after the cut between the different editing styles for alpha frequencies $(8-12 \mathrm{~Hz})$, which have been related in many studies to changes in attention (Sauseng et al., 2005), as well as for beta frequencies $(12-20 \mathrm{~Hz}$ and $20-28 \mathrm{~Hz})$, in two brain areas: the occipital and the frontal. The occipital area is in charge of managing visual perception, while higher cognitive processing such as understanding and decision-making occurs in the frontal area.

On the other hand, we also analyzed the event-related potentials (ERPs) after the cuts based on the different editing styles, again finding differences in the occipital area (visual processing) and frontal area (higher cognitive processing, comprehension) between the two editing styles (see Figure 2). The differences were statistically significant ( $p<0.05$, t-test) and showed greater electrical activity in the occipital area of the viewers watching the audiovisual content with a chaotic and disorganized editing style compared with the classical editing style. Meanwhile, the activity in the frontal area was higher when watching the video with the classical versus chaotic editing style.

\section{Discussion and conclusions}

In our previous research (Andreu-Sánchez et al., 2017a; 2017b; 2018) we found that the cutting and editing style of audiovisual material affects the cognitive processing of viewers. The segmentation of audiovisual content depends on significant changes in the content and their perception (Zacks et al., 2010). The editing style affects viewers' blink rate (Andreu-Sánchez et al., 2017b). An editing style with no cuts increases this rate, while a chaotic style with many cuts decreases it. Assu-
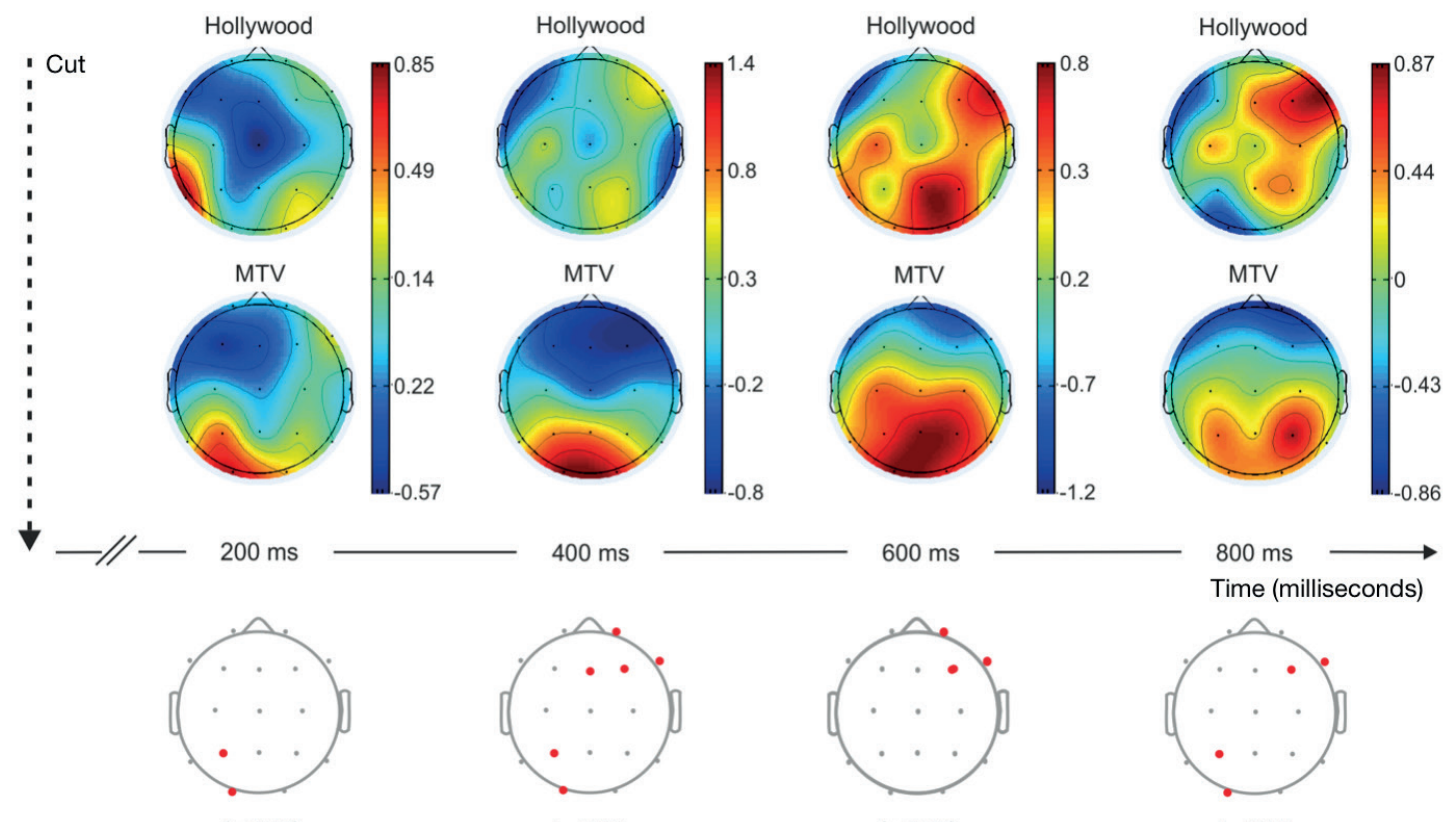

$600 \mathrm{~ms}$

Time (milliseconds)

$$
(p<0.05)
$$

$$
(p<0.05)
$$

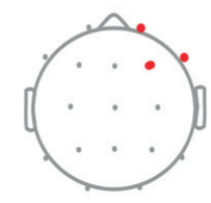

$(p<0.05)$

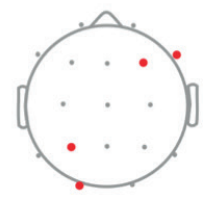

$(p<0.05)$

Figure 2. Topographic maps of the mean brain activity after the cuts for both editing styles. Four time points after the cut are displayed: 200 milliseconds (ms), $400 \mathrm{~ms}, 600 \mathrm{~ms}$, and $800 \mathrm{~ms}$. The upper colored panels show the results for the classic, Hollywood editing style, while the lower colored panels show the results for the chaotic editing style, as in MTV-style video clips. Red areas indicate an increase in activity, and blue areas a decrease. In the lower panels, statistically significant differences found (t-test) between the two styles are indicated by red dots. Source: authors' illustration, reprinted from Andreu-Sánchez et al. (2018) with permission from Elsevier. 
ming that blinking is a marker of attention (Fogarty; Stern, 1989), we can conclude that the chaotic editing style increases viewers' attention while classical editing with organized cuts fails to provoke such an increase in attention. In turn, the fixed-shot sequence diminished the attention of the observer. It is thus apparent that the cuts and, in particular, the editing style in general can be used by creators of audiovisual content to manage the audience's attention.

Continuity or discontinuity in editing leads to perceptual differences in the viewers (Heimann et al., 2016). The chaotic and disorganized style results in greater activity in the visual processing of the spectators compared with the classical and orderly style (Andreu-Sánchez et al., 2018). This could be because the chaotic style requires more activity in the occipital area that is responsible for visual processing to be able to decode the visual information presented. When the editing is chaotic, the shots do not maintain organization or coherence with the previous ones and breaks in time and space are presented regularly. This would result in extra work by the viewers to see and process these cuts. At the same time, shots in the ordered classical editing style do obey continuity of time and space, are clear, and present visual information without blurring or abrupt movements. This would make it unnecessary for the visual cortex to "work" so hard to decode each of the shots after the cuts.

Regarding the differences found in the frontal area (Andreu-Sánchez et al., 2018), we can conclude that, although the classical editing style requires less work on the part of the visual cortex to decode the elements of visual perception, it does generate more activity in the frontal area. Considering that this area is related to higher cognitive processes (comprehension, analysis, understanding, decision-making, etc.), we can conclude that the classical editing style provokes greater cognitive processing of this type. Therefore, a chaotic and disorganized editing style, while harder to decode visually, is not necessarily better understood by viewers.

These results verify that both the cuts and the audiovisual editing style affect the perception and understanding of the viewers. This should be immediately incorporated into training plans in the Communication Sciences, so that creators and editors of cinematographic, informational, advertising, educational content, etc. can apply this knowledge to the strategies of each genre.

Much further research is needed, especially in the area of audiovisual content and its cerebral perception, beyond the rhythm of editing, which is essential in the management of audiovisual attention. It also seems convenient to incorporate neuroscientific techniques into the Communication Sciences (Martín-Pascual et al., 2018) in order to expand knowledge in the new areas that have emerged at the frontier between neuroscience and communication (Martín-Pascual; Andreu-Sánchez, 2015) and, specificaIly, to delve into the findings of nascent neurocinematics.

\section{Note}

1. This article was presented in communication format at the VII Congreso Internacional de la Asociación Española de Investigación de la Comunicación ( $A E-I C$ ), Valencia, October 28-30, 2020. By agreement with $A E-I C$ it was selected, peer-reviewed in double anonymity, and approved for publication in this journal.

\section{References}

Andreu-Sánchez, Celia; Martín-Pascual, Miguel-Ángel; Gruart, Agnès; Delgado-García, José-María (2017a). «Looking at reality versus watching screens: Media professionalization effects on the spontaneous eyeblink rate». PLoS one, v. 12, n. 5, e0176030. https://doi.org/10.1371/journal.pone.0176030

Andreu-Sánchez, Celia; Martín-Pascual, Miguel-Ángel; Gruart, Agnès; Delgado-García, José-María (2017b). «Eyeblink rate watching classical Hollywood and post-classical MTV editing styles, in media and non-media professionals». Scientific reports, v. 7, 43267.

https://doi.org/10.1038/srep43267

Andreu-Sánchez, Celia; Martín-Pascual, Miguel-Ángel; Gruart, Agnès; Delgado-García, José-María (2018). «Chaotic and fast audiovisuals increase attentional scope but decrease conscious processing». Neuroscience, n. 394, pp. 83-97. https://doi.org/10.1016/j.neuroscience.2018.10.025

Berger, Hans (1929). «Über das elektrenkephalogramm des menchen». Archives für psychiatrie, v. 278, n. 87, pp. 527-570.

Blehm, Clayton; Vishnu, Seema; Khattak, Ashbala; Mitra, Shrabanee; Yee, Richard W. (2005). «Computer vision syndrome: a review». Survey of ophthalmology, v. 50, n. 3, pp. 253-62.

https://doi.org/10.1016/j.survophthal.2005.02.008

Bordwell, David; Staiger, Janet; Thompson, Kristin (1985). Classical Hollywood cinema: Film style and mode of production to 1960. London: Routledge. ISBN: 9780415003834 
Bour, Lo J.; Aramideh, Majid; Ongerboer-de-Visser, Bram W. (2000). «Neurophysiological aspects of eye and eyelid movements during blinking in humans». Journal of neurophysiology, v. 83, n. 1, pp. 166-176.

http://jn.physiology.org/content/83/1/166.short

Bristow, Davina; Haynes, John-Dylan; Sylvester, Richard; Frith, Christopher D.; Rees, Geraint (2005). «Blinking suppresses the neural response to unchanging retinal stimulation». Current biology, v. 15, n. 14, pp. 1296-1300.

https://doi.org/10.1016/j.cub.2005.06.025

Byrne, John (2015). «Propagation of the action potential». Neuroscience on line. Department of Neurobiology and Anatomy, The UT Medical School at Houston.

https://nba.uth.tmc.edu/neuroscience

Cochin, Stephanie; Barthelemy, Catherine; Roux, Sylvie; Martineau, Joelle (1999). «Observation and execution of movement: Similarities demonstrated by quantified electroencephalography». European journal of neuroscience, v. $11, \mathrm{n}$. 5, pp. 1839-1842.

https://doi.org/10.1046/j.1460-9568.1999.00598.x

Cohen-Séat, Gilbert; Gastaut, Henri; Bert, Jacques (1954). «Modification de l’E.E.G. pendant la projection cinématographique». Revue internationale de filmologie, v. 5, n. 16, pp. 7-25.

Delgado-García, José M.; Gruart, Agnès; Múnera, Alejandro (2002). «Neural organization of eyelid responses». Movement disorders: official journal of the Movement Disorder Society, v. 17, Suppl 2, pp. S33-S36.

https://doi.org/10.1002/mds.10055

Finn, Emily S.; Shen, Xilin; Scheinost, Dustin; Rosenberg, Monica D.; Huang, Jessica; Chun, Marvin M.; Papademetris, Xenophon; Constable, R. Todd (2015). «Functional connectome fingerprinting: Identifying individuals using patterns of brain connectivity». Nature neuroscience, v. 18, n. 11, pp. 1664-1671.

https://doi.org/10.1038/nn.4135

Fogarty, Christine; Stern, John A. (1989). «Eye movements and blinks: their relationship to higher cognitive processes». International journal of psychophysiology, v. 8, n. 1, pp. 35-42.

https://doi.org/10.1016/0167-8760(89)90017-2

Gastaut, Henri; Bert, Jacques (1954). «EEG changes during cinematographic presentation (moving picture activation of the EEG)». Electroencephalography and clinical neurophysiology, v. 6, n. 3, pp. 433-444.

https://doi.org/10.1016/0013-4694(54)90058-9

Germeys, Filip; D’Ydewalle, Géry (2007). «The psychology of film: perceiving beyond the cut». Psychological research, v. 71, n. 4, pp. 458-66.

https://doi.org/10.1007/s00426-005-0025-3

Hasson, Uri; Landesman, Ohad; Knappmeyer, Barbara; Vallines, Ignacio; Rubin, Nava; Heeger, David J. (2008). «Neurocinematics: The neuroscience of film». Projections, v. 2, n. 1, pp. 1-26.

https://doi.org/10.3167/proj.2008.020102

Hasson, Uri; Nir, Yuval; Levy, Ifat; Fuhrmann, Galit; Malach, Rafael (2004). «Intersubject synchronization of cortical activity during natural vision». Science (New York, N.Y.), v. 303, n. 5664, pp. 1634-40.

https://doi.org/10.1126/science.1089506

Heimann, Katrin S.; Uithol, Sebo; Calbi, Marta; Umiltà, Maria A.; Guerra, Michele; Gallese, Vittorio (2016). «'Cuts in action': A high-density EEG study investigating the neural correlates of different editing techniques in film». Cognitive science, v. 41, n. 6, pp. 1-34.

https://doi.org/10.1111/cogs.12439

Magliano, Joseph P.; Zacks, Jeffrey M. (2011). «The impact of continuity editing in narrative film on event segmentation». Cognitive science, v. 35, n. 8, pp. 1489-517.

https://doi.org/10.1111/j.1551-6709.2011.01202.x

Martín-Pascual, Miguel-Ángel; Andreu-Sánchez, Celia (2015). «Entre la neurociencia y la comunicación: nuevas áreas de conocimiento». En: Líneas emergentes en la investigación de vanguardia. Madrid: McGrawHill, pp. 365-378. ISBN: 9788448197414

Martín-Pascual, Miguel-Ángel; Andreu-Sánchez, Celia; Delgado-García, José-María; Gruart, Agnès (2018). «Using electroencephalography measurements and high-quality video recording for analyzing visual perception of media content». JoVE - Journal of visualized experiments, n. 135, e57321.

https://doi.org/10.3791/57321

Milner, David A.; Goodale, Melvyn A. (2006). The visual brain in action. Norfolk, Britain: Oxford University Press. ISBN: 9780198524724 
Mountcastle, Vernon B. (1978). «An organizing principle for cerebral function: the unit module and the distributed system». In: The mindful brain, MIT Press. ISBN: 9780262550079

Mountcastle, Vernon B. (1998). Perceptual Neuroscience. The cerebral cortex. Cambridge, Massachusetts: Harvard University Press. ISBN: 0674661885

Münsterberg, Hugo (1916). The photoplay, New York: Appleton and Company. ISBN: 9781406594959

Murch, Walter (1995). In the blink of an eye: A perspective on film editing, Beverly Hills, California: Silman-James Press. ISBN: 1879505622

Nakano, Tamami; Yamamoto, Yoshiharu; Kitajo, Keiichi; Takahashi, Toshimitsu; Kitazawa, Shigeru (2009). «Synchronization of spontaneous eyeblinks while viewing video stories». Proceedings. Biological sciences / The Royal Society, v. 276, pp. 3635-3644.

https://doi.org/10.1098/rspb.2009.0828

Rizzolatti, Giacomo; Craighero, Laila (2004). «The mirror-neuron system». Annual review of neuroscience, v. 27, pp. 169-192.

https://doi.org/10.1146/annurev.neuro.27.070203.144230

Sauseng, Paul; Klimesch, Wolfgang; Stadler, Waltraud; Schabus, Manuel; Doppelmayr, Michael; HansImayr, Simon; Gruber, Walter R.; Birbaumer, Niels (2005). «A shift of visual spatial attention is selectively associated with human EEG alpha activity». European journal of neuroscience, v. 22, n. 11, pp. 2917-2926.

https://doi.org/10.1111/j.1460-9568.2005.04482.x

Shapiro, Kimron; Arnell, Karen; Raymond, Jane (1997). «The attentional blink». Trends in cognitive sciences, v. 1, n. 8, pp. 291-296.

http://www.scholarpedia.org/article/Attentional_blink

Skotte, Jørgen H.; Nøjgaard, Jacob-Klenø; Jørgensen, Lars V.; Christensen, Karl-Bang; Sjøgaard, Gisela (2007). «Eye blink frequency during different computer tasks quantified by electrooculography». European journal of applied physiology, v. 99, n. 2, pp. 113-119.

https://doi.org/10.1007/s00421-006-0322-6

Smith, Tim J. (2012). «The attentional theory of cinematic continuity». Projections, v. 6, n. 1, pp. 1-27.

https://doi.org/10.3167/proj.2012.060102

Smith, Tim J.; Henderson, John M. (2008). «Edit blindness: The relationship between attention and global change blindness in dynamic scenes». Journal of eye movement research, v. 2, n. 6, pp. 1-17.

https://doi.org/10.16910/jemr.2.2.6

Stern, John A.; Boyer, Donna; Schroeder, David (1994). «Blink rate: a possible measure of fatigue». Human factors, v. 36, n. 2, pp. 285-97.

Thorpe, Simon; Fize, Denis; Marlot, Catherine (1996). «Speed of processing in the human visual system». Nature, v. 381, n. 6, pp. 520-522.

https://doi.org/10.1038/381520a0

VanRullen, Rufin (2007). "The blinking spotlight of attention». Proceedings of the National Academy of Sciences of the United States of America, v. 104, n. 49, pp. 19204-19209.

http://www.pnas.org/content/104/49/19204.short

VanRullen, Rufin; Thorpe, Simon J. (2001). «The time course of visual processing: From early perception to decision-making». Journal of cognitive neuroscience, v. 13, n. 4, pp. 454-461.

https://doi.org/10.1162/08989290152001880

Wong, K. K. W.; Wan, W. Y.; Kaye, Stephen B. (2002). «Blinking and operating: cognition versus vision». British journal of ophthalmology, n. 86, p. 476.

https://doi.org/10.1136/bjo.86.4.479

Zacks, Jeffrey M.; Speer, Nicole K.; Swallow, Khena M.; Braver, Todd S.; Reynolds, Jeremy R. (2007). «Event perception: a mind-brain perspective». Psychological bulletin, v. 133, n. 2, pp. 273-93.

https://doi.org/10.1037/0033-2909.133.2.273

Zacks, Jeffrey M.; Speer, Nicole K.; Swallow, Khena M.; Maley, Corey J. (2010). «The brain's cutting-room floor: segmentation of narrative cinema». Frontiers in human neuroscience, v. 4, n. October, pp. 1-15.

https://doi.org/10.3389/fnhum.2010.00168

Zola-Morgan, Stuart (1995). «Localization of brain function: the legacy of Franz Joseph Gall (1758-1828)». Annual review of neuroscience, n. 18, pp. 359-383.

https://www.annualreviews.org/doi/abs/10.1146/annurev.ne.18.030195.002043 